\title{
A QUESTÃO DA ENERGIA NA CONTEMPORANEIDADE: AÇÕES E DESAFIOS
}

\author{
Danilo Coutinho da Silva ${ }^{1}$
}

Paulo Vitor Nascimento de Freitas ${ }^{2}$

\begin{abstract}
RESUMO
Muitos países vêm fazendo grande esforço e investindo grandes quantias para diminuir o impacto das fontes de energia não renováveis, mas dessa forma não combatem as emissões de carbono e acabam alimentando a dependência de países em desenvolvimento, sensíveis à variabilidade nos preços dos combustíveis fósseis, que dominam a matriz energética mundial. As energias renováveis reduzem esse problema, pois são menos poluentes e fomentam a geração de emprego. Além da mudança nas fontes de energia é preciso garantir maior eficiência e mais acesso às suas formas modernas, ainda mais em um contexto de crescimento populacional. Este trabalho objetiva discutir a questão da energia na contemporaneidade, mostrando a situação atual no mundo, apontando algumas ações adotadas e os desafios enfrentados pelos países na transição para uma matriz energética eficiente, limpa e renovável. Para tanto, entre os procedimentos metodológicos estão a pesquisa bibliográfica, o levantamento de dados acerca da geração de energia no mundo por fonte, análise dos dados e produção do texto final. Com base na pesquisa, conclui-se que as fontes renováveis ganharam importância nos últimos anos, mas ainda há muito o que se avançar nesse campo e também em eficiência energética, fatores essenciais para reduzir as emissões de $\mathrm{CO} 2$ e combater as mudanças climáticas.
\end{abstract}

PALAVRAS-CHAVE: Energia. Energias renováveis. Eficiência energética.

\section{THE ISSUE OF ENERGY IN CONTEMPORANEITY: ACTIONS}

\section{AND CHALLENGES}

\begin{abstract}
Many countries are making great effort and investing large amounts of money to reduce the impact of non-renewable energy sources, but in this way, they do not reduce carbon emissions and fuel the dependence of developing countries, more sensitives to variability in the prices of fossil fuels, which dominate the world energy matrix. Renewable energies reduce this problem because they are less polluting and create jobs. Besides the change in the sources of energy we need to ensure greater efficiency and greater access to its modern forms, especially in a context of population growth. This work aims to discuss the issue of energy today, showing the current situation in the world, pointing out some actions taken and challenges faced by countries in transition to an efficient, clean and renewable energy matrix. To this end, among the methodological procedures are the bibliographical research, data collection about power generation in the world by energy source, data analysis and production of the final text. Based

\footnotetext{
${ }^{1}$ Geógrafo e Especialista em Ciências Ambientais, CINTEP/FNSL. danilocoutinhogeo@gmail.com.

${ }^{2}$ Geógrafo e Mestrando em Engenharia Civil e Ambiental, PPGECAM/UFPB. pauloge05@gmail.com.
} 


\section{Periádica Eletrânica

on the research, it is concluded that renewable sources have gained importance in recent years, but there is still much to advance in this field and also in energy efficiency, key factors to reduce $\mathrm{CO} 2$ emissions and combat climate change.

KEYWORDS: Energy. Renewable energy. Energy efficiency.

\section{LA CUESTIÓN DE LA ENERGÍA EN LA CONTEMPORANEIDAD: ACCIONES Y DESAFÍOS}

\section{RESUMEN}

Muchos países están haciendo un gran esfuerzo y invirtiendo grandes sumas de dinero para reducir el impacto de las fuentes de energía no renovables, pero de esta manera, no reducen efectivamente las emisiones de carbono y terminan alimentando la dependencia de los países en desarrollo sensibles a la variabilidad de los precios de los combustibles fósiles, que dominan la matriz energética mundial. Las energías renovables reducen este problema, ya que son más limpios e incluso crean puestos de trabajo. Además del cambio en las fuentes de energía, tenemos que garantizar una mayor eficiencia y un mayor acceso a sus formas modernas, especialmente en un contexto de crecimiento poblacional. Este trabajo tiene como objetivo discutir el tema de la energía hoy en día, mostrando la situación actual en el mundo, señalando algunas acciones tomadas y los desafíos que enfrentan los países en la transición hacia una base de energía eficiente, limpia y renovable. Para ello, entre los procedimientos metodológicos están revisión de la literatura, la recopilación de datos sobre la generación de energía en el mundo por la fuente de energía, análisis de datos y elaboración del texto final. Basado en la investigación, se concluye que las fuentes renovables han ganado importancia en los últimos años, pero aún queda mucho por avanzar en este campo y también en la eficiencia energética, factores clave para reducir las emisiones de CO2 y combatir el cambio climático.

PALABRAS CLAVE: Energía. Energias renovables. La eficiencia energética.

\section{INTRODUÇÃO}

Muitos países vêm fazendo grande esforço e investindo grandes quantias para tentar diminuir o impacto das fontes de energia não-renováveis, 0 mercado de captura de carbono movimenta bilhões de dólares, porém os resultados não são satisfatórios e o padrão de extração dos recursos mantémse insustentável. Além disso, alimenta-se a dependência de países em desenvolvimento, que ficam sujeitos a variabilidade dos preços dos combustíveis fósseis.

As energias renováveis reduzem esses problemas, pois são menos poluentes, com menores emissões de carbono, e ainda fomentam a geração de empregos. Em todo o mundo estima-se que na geração de energia renovável são empregadas mais de 7,7 milhões de pessoas, mais da metade delas na China (REN21, 2015). 
É preciso também investir em eficiência energética e levar o acesso à energia para milhões de pessoas. Segundo a ONU (2012), cerca de $20 \%$ da população mundial, ou seja, quase 1,5 bilhão de pessoas, não tinha acesso a formas modernas de eletricidade em 2012. Além disso, cerca de 3 bilhões ainda usam fontes poluentes e esgotáveis de energia, contribuindo para que a geração de energia seja responsável por cerca de $60 \%$ das emissões de gases que provocam o efeito estufa.

$\mathrm{Na}$ Conferência das Nações Unidas sobre Desenvolvimento Sustentável, a Rio+20, os países se comprometeram a aumentar a participação das fontes limpas e renováveis na geração total de energia no mundo. Esse fator poderia representar também uma melhora na qualidade de vida da população do planeta, trazendo melhorias nas suas condições sociais, principalmente na saúde e no atendimento das necessidades básicas da sociedade.

Para a $21^{\text {a }}$ Conferência do Clima (COP21) organizada pela ONU, que será realizada em Paris no fim de 2015, são esperados novos compromissos a serem firmados entre os países participantes para aumentar a participação de fontes renováveis na matriz energética mundial, com o intuito de combater as mudanças climáticas.

A mudança no perfil da geração de energia mundial se torna ainda mais necessária em um contexto de crescimento populacional. Até 2040 o mundo deve atingir a marca de 9 bilhões de habitantes e nos próximos 20 anos a classe média deve ganhar 3 bilhões de pessoas, que consumirão $45 \%$ mais energia até 2013, tornando ainda mais difícil o acesso universal a esse recurso (ONU, 2012).

Esse trabalho objetiva discutir a questão da energia na atualidade, mostrando a situação do quadro energético mundial, apontando algumas ações adotadas e os desafios enfrentados pelos países na transição para uma matriz energética eficiente, limpa e renovável.

Para alcançar esse objetivo, entre os procedimentos metodológicos estão a pesquisa bibliográfica sobre o tema; o levantamento de dados secundários acerca da situação atual da geração de energia no mundo por 
fonte, encontrados nos documentos oficiais das agências internacionais de energia; análise dos dados e produção do texto final.

\section{A MATRIZ ENERGÉTICA MUNDIAL E A NECESSIDADE DE MUDANÇA}

Segundo a The International Energy Agency (IEA) energia renovável pode ser definida, genericamente, como aquela derivada de processos naturais e que é reposta constantemente (IEA, 2005). Há várias formas de energias renováveis existentes, entre elas estão as formas de energia geradas a partir do vento, da biomassa, da força da água e dos oceanos, a geotérmica, o biogás e os biocombustíveis e a energia solar. Todas derivando, direta ou indiretamente, do sol ou do calor interno da Terra.

A despeito dessa variedade de fontes energéticas renováveis e das possibilidades de exploração das mesmas, os combustíveis fósseis continuam dominando a matriz energética global, respondendo atualmente por mais de $80 \%$ da oferta e por $66 \%$ do consumo final.

Figura 1: Oferta mundial de energia por fonte, 2012

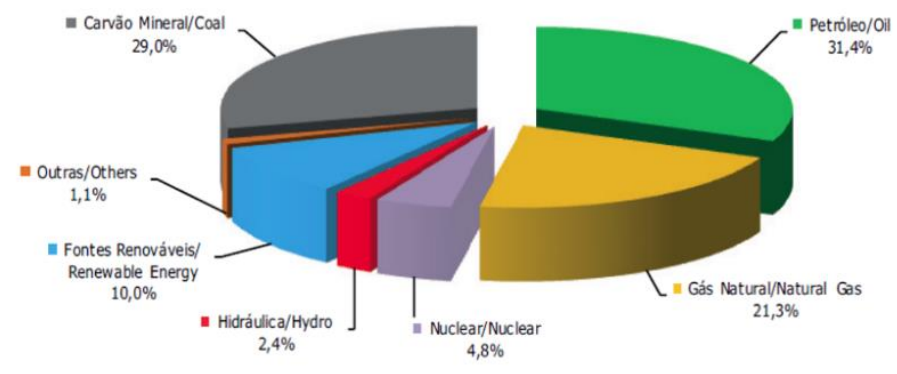

Fonte: EPE, 2015

Figura 2: Consumo mundial de energia por fonte, 2012

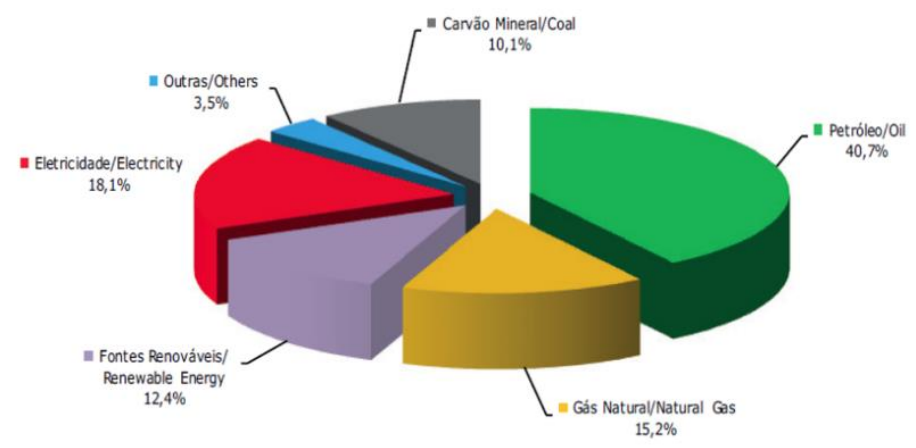

Fonte: EPE, 2012 
Os combustíveis fósseis são fontes esgotáveis de energia, formados a partir da decomposição de matéria orgânica soterrada há milhões de anos, que dependendo da origem e dos processos de formação, se apresentam de diferentes formas, as principais são o petróleo, o carvão mineral e o gás natural, respectivamente, em termos de oferta.

O setor de energia é responsável por dois terços das emissões de gases do efeito estufa de origem antropogênica. A IEA prevê que, mantendo-se a tendência atual, até 2040 as emissões de CO2 pelo setor energético devem aumentar $20 \%$, gerando a longo prazo um aumento da temperatura global em torno de $3,6^{\circ} \mathrm{C}$, ou seja, acima dos $2 \%$ acordados internacionalmente (IEA, 2014).

Essa tendência vem causando prejuízos não só ambientais, mas à economia de países em desenvolvimento, principalmente da África, que comprometem boa parte de suas receitas com a importação de petróleo bruto. O problema se estende para outros continentes, a Índia, por exemplo, compromete cerca de $45 \%$ de suas receitas de importação, ficando sujeita aos aumentos e a variação dos preços do produto no mercado internacional (PNUMA, 2011).

Os combustíveis fósseis ainda travam o investimento em eficiência energética e a transição definitiva para 0 uso das energias renováveis. Em 2013 os subsídios atingiram 550 bilhões de dólares, mais de quatro vezes o valor dos subsídios em energias renováveis, cerca de 120 bilhões (IEA, 2014).

Para Goldemberg e Lucon (2006-2007) a situação atual é insustentável por quatro motivos: o primeiro leva em consideração o fato da matriz energética atual ser baseada em fontes esgotáveis, como o petróleo, cujas reservas estariam próximas do limite, considerando o nível de consumo. O segundo é o prejuízo ao meio ambiente, principalmente com os impactos das mudanças climáticas. O terceiro motivo diz respeito aos conflitos regionais, seja por disputas pelo petróleo ou pelo uso bélico da energia nuclear. $O$ último é a pressão exercida sobre a dívida externa dos países em desenvolvimento, dependentes da importação dos derivados do petróleo. 
Mudar essa realidade é um grande desafio para o mundo nas próximas décadas, principalmente nas áreas de aquecimento e de transportes, onde ainda predominam as energias não-renováveis. Por isso é imprescindível o aumento da participação das energias renováveis na matriz das grandes economias globais.

Apesar das dificuldades, nos últimos anos vem sendo assinaladas algumas mudanças. A IEA, em seu estudo sobre energia e mudança climática, destacou que as energias renováveis representaram quase metade de toda a nova capacidade de geração de energia em 2014 (cerca de 128 GW). Isso foi possível graças ao crescimento dos investimentos, liderados pela China, Estados Unidos, Japão e Alemanha, e também pela redução dos custos na sua geração (IEA, 2015).

A China continua a liderar as novas instalações de capacidade de energia renovável. Já Brasil, Índia e África do Sul foram responsáveis por uma grande parte da capacidade adicionada em suas respectivas regiões em 2014 e um número cada vez maior de países em desenvolvimento na Ásia, África e América Latina começam a implantar e produzir importantes tecnologias renováveis (REN21, 2015).

O setor elétrico vem impulsionando essa transformação no quadro energético atual, a IEA (2014) aponta que a eletricidade é a forma de energia final que mais contribui para a redução da participação dos combustíveis fósseis na matriz mundial. O Brasil é um exemplo dessa realidade, 74,6\% da oferta de eletricidade no país provém de fontes renováveis, apesar de ter registrado um aumento no uso de fontes não-renováveis no último ano, notadamente o gás natural, $13 \%$ da oferta (BRASIL, 2015).

Espera-se mais mudanças a partir da COP 21, conferência sobre 0 clima que acontecerá em Paris, em dezembro de 2015, onde os países deverão discutir novas medidas e traçar novas metas para a redução nas emissões de CO2. Ações efetivas no setor energético são essenciais para se atingir esse objetivo e combater as alterações climáticas. 


\section{ENERGIAS RENOVÁVEIS: QUADRO ATUAL}

Goldemberg e Lucon (2006-2007) classificam as energias renováveis em tradicionais e modernas, estas podem ser subdivididas ainda em "convencionais" e "novas". As fontes convencionais são utilizadas há muito tempo, como as usinas hidrelétricas de médio e grande porte. As fontes novas são aquelas que começaram a ser usadas em larga escala recentemente, é o caso da energia eólica, solar fotovoltaica, biomassa moderna, etc. Essas novas fontes são as que mais crescem atualmente, contribuindo para mudar um pouco a realidade da geração de energia global.

\subsection{Energia eólica}

A energia eólica foi responsável por $37 \%$ dos 128 GW de energias renováveis instalados em 2014 no mundo, representando a maior parte do crescimento na geração de energia limpa (IEA, 2015). A capacidade total no mundo chegou a $370 \mathrm{GW}$ de acordo com o Renewable Energy Policy Network for the 21st Century (REN21, 2015).

A China é a líder mundial em termos de capacidade instalada de energia eólica, até o fim de 2013 a capacidade total do país chegou a 91,4 GW, com crescimento de 16,1 GW, apenas nesse ano, segundo dados do Global Wind Energy Council (GWEC, 2014). A meta do governo chinês é chegar a 200 GW até 2020.

Na produção de eletricidade, as fontes renováveis foram responsáveis por 20\% da geração total em 2013 (maior parte de origem hidrelétrica), embora $74 \%$ ainda tenha origem em centrais elétricas a carvão, que vem passando por redução de custos, o que dificulta ainda mais o investimento em energias limpas no país (GWEC, 2014, p.31). Também é preciso que haja mais investimentos em infraestrutura para levar a eletricidade produzida através dos ventos para a população de regiões remotas e centros industriais, dificuldade ainda enfrentada pela China.

Além da China, Estados Unidos e Alemanha também se destacam. Em 2013, a Alemanha contava com capacidade de mais de 34 GW, 3 GW só no 
referido ano. Já os Estados Unidos chegaram a $61 \mathrm{GW}$, graças à entrada de grandes nomes da tecnologia no negócio (GWEC, 2014). Ainda segundo o GWEC, o Brasil tem um potencial gigantesco na geração de energia eólica, porém constata-se que este potencial ainda é pouco aproveitado. Esse tipo de energia corresponde a apenas $2 \%$ de toda oferta interna de energia elétrica, em 2013 a sua capacidade total era de 3,4 GW, com expectativa de dobrá-la até o fim de 2015.

Um benefício a mais da energia eólica é a possibilidade de uso duplo, ou seja, da convivência com outras atividades econômicas, notadamente a atividade agrícola, que pode compartilhar as terras destinadas ao plantio com as torres dos aerogeradores (EVANS et al., 2009).

\subsection{Energia solar}

Segunda fonte mais representativa na geração de energia renovável em 2014, a energia solar foi responsável por quase $30 \%$ da nova capacidade energética instalada no mundo no ano passado (IEA, 2015). O seu custo de implantação ainda é alto, mas vem sendo reduzido nos últimos anos, tornando mais viável o investimento nessa fonte. Mais de $60 \%$ de toda a capacidade fotovoltaica do mundo foi instalada nos últimos três anos, atingindo $177 \mathrm{GW}$ de capacidade total (REN21, 2015).

A energia solar fotovoltaica expandiu-se fortemente na Ásia, principalmente na China e no Japão, com capacidades de 28 GW e 23,3 GW, respectivamente. Os chineses produzem dois terços das placas fotovoltaicas do mundo (há uma década produziam apenas 5\%) e empregam mais de 2,5 milhões de pessoas na atividade. Apesar desse crescimento, a Alemanha ainda possui a maior capacidade instalada, com 38,2 GW (REN21, 2015).

Os impactos da energia solar praticamente se resumem ao descarte dos materiais usados na fabricação das placas fotovoltaicas, também necessita de uma grande área para produção em larga escala, mas o uso da terra pode ser minimizado se as placas forem montadas sobre telhados de casas e prédios. 


\subsection{Energia hidrelétrica}

A energia hidrelétrica foi a terceira que mais cresceu entre as fontes renováveis em 2014 e ainda é a mais representativa em termos de capacidade instalada, acumulando 1.055 GW (REN21, 2015). Na geração global de eletricidade, $16 \%$ provém dessa fonte, conforme dados da International Hydropower Association (IHA, 2015).

A China também é a líder mundial em capacidade e geração de energia através de hidrelétricas, com um total de $280.000 \mathrm{MW}$. Ela é seguida por Brasil (89.306 MW), Canadá (77.558 MW), Estados Unidos (79.270 MW) e Rússia (49.108 MW). O país asiático adicionou incríveis 21.250 MW em sua capacidade apenas em 2014. O Brasil foi o segundo que mais cresceu, adicionando no ano $3.312 \mathrm{MW}$, mesmo passando por um período de estiagem, que prejudica a geração de energia hidrelétrica. Esse fator acarretou 0 aumento do uso de combustíveis fósseis no país, principalmente do gás natural (IHA, 2015).

Para Evans et al (2009) a instalação das hidrelétricas é controversa, pois a inundação para a formação das barragens resulta no deslocamento de pessoas e animais, na perda de vegetação, de áreas agrícolas e pastagens, podendo causar um grande impacto social. Porém pode também beneficiar as comunidades quando proporciona um melhor controle de inundação e garante acesso à água e irrigação durante todo $o$ ano.

\subsection{Biomassa moderna}

A biomassa também é uma fonte de energia renovável que, segundo Goldemberg e Lucon (2006-2007), pode ser dividida em duas subcategorias: a biomassa primitiva ou tradicional, como a lenha; e a biomassa "moderna", representada pela lenha replantada e por culturas energéticas, como a canade-açúcar e os óleos vegetais.

Em 2013, de toda a energia produzida, 19,1\% foram de fontes renováveis, dessa cota $9 \%$ é de biomassa tradicional, usada para cozinhar e aquecer em áreas remotas e rurais de países em desenvolvimento, a maioria 
na África, as energias renováveis modernas contemplam os outros $10,1 \%$ (REN21, 2015).

A chamada biomassa moderna dá origem aos biocombustíveis, usados para aquecimento, na geração de eletricidade e no setor de transportes, onde a participação de fontes renováveis ainda é pequena, mas crescente, principalmente de biocombustíveis líquidos.

Na produção de biocombustíveis Estados Unidos e Brasil lideram, com produção de 60,1 e 29,9 bilhões de litros, respectivamente. Alemanha, China e Argentina vêm logo em seguida, mas juntas produzem menos de 12 bilhões de litros (REN21, 2015). Dentre os biocombustíveis líquidos, destacam-se o etanol e o biodiesel, com grande contribuição no setor de transportes, consideravelmente maior em alguns países europeus, nos Estados Unidos e no Brasil, onde a participação dos biocombustíveis no transporte rodoviário chegou a 20\% em 2014 (REN21, 2015). Esse crescimento foi puxado pelo aumento da adição de etanol na gasolina, de $25 \%$ para $27 \%$, e do biodiesel no diesel comum, de 5\% para 7\% (IEA, 2015).

A adição de biocombustível na gasolina não é recente, começou no Brasil em 1975 com o Proálcool, no contexto da crise do petróleo. A partir daí o desenvolvimento tecnológico e a gradual redução dos custos tornaram o etanol um combustível competitivo no mercado em relação à gasolina.

\subsection{Energias maremotriz e geotérmica}

Duas fontes renováveis de energia importantes, mas menos conhecidas e utilizadas, são a geotérmica e a maremotriz. A primeira gera calor e eletricidade através do aproveitamento do calor natural do interior da terra em regiões onde são comuns gêiseres e vulcões. E a segunda gera eletricidade através do movimento das marés e ondas.

Segundo a Geothermal Energy Association (GEA, 2013) a capacidade geotérmica global instalada em 2013 era de 11.765 MW, embora estima-se que essa pode ser dobrada com os projetos em desenvolvimento ou em construção em mais de 70 países e territórios. O país com maior capacidade instalada são 
os Estados Unidos com 3.388 MW, também se destacam as Filipinas (1.884 MW), a Indonésia (1.333 MW), o México (980 MW) e a Itália (901 MW).

O Japão, que desde o acidente nuclear de Fukushima, vem procurando investir em fontes energéticas mais limpas, reviveu seu projeto geotérmico que estava estagnado. A capacidade atual do país é de $537 \mathrm{MW}$ e há quatro projetos em construção, porém o investimento ainda esbarra em uma série de regulamentações (GEA, 2013). Isso porque, apesar das usinas geotérmicas emitirem poucos gases poluentes, sua produção pode acarretar a subsidência do terreno nas áreas exploradas (TAIOLI, 2008).

Ainda pouco explorada, a energia maremotriz tem apenas $498 \mathrm{MW}$ de capacidade instalada em todo o mundo, $240 \mathrm{MW}$ são gerados na central de La Rance, França, operada desde 1967. A mais recente central energética é a do Lago Sihwa na Coreia do Sul, inaugurada em 2011, é a maior barragem de marés do mundo, com capacidade de 254 MW (IRENA, 2014).

Os altos custos, as especificidades envolvidas em sua exploração e os inevitáveis impactos ambientais na construção de barragens, vem impedindo o avanço da energia maremotriz, levando os investimentos governamentais e de empresas para outras fontes renováveis, mais populares e baratas.

\section{EFICIÊNCIA ENERGÉTICA}

A mudança na base mundial de produção de energia, com o aumento da utilização de fontes renováveis é um grande passo, mas não o único a ser dado, outro importante fator para tornar a geração de energia mais sustentável é o investimento em eficiência energética. Essas duas ações associadas tendem a proporcionar uma transformação muito maior tanto na produção quanto no consumo mundial de energia.

Para o REN21 (2015) as políticas destinadas a promover a melhoria na eficiência incluem o aumento da segurança energética, apoiar o crescimento econômico e mitigar a mudança climática. Geralmente, os processos mais eficientes exigem menos requisitos de produção, além de menores custos operacionais e de capital (EVANS et al., 2009). Nos países mais pobres, a 
maior eficiência energética pode, ainda, tornar mais viável a universalização do acesso aos serviços energéticos.

A eficiência energética é um fator importante a se considerar e deve ser perseguida por todos os países. As escolhas envolvidas nesse campo vão variar de acordo com as características físicas e com as possibilidades tecnológicas de cada um.

\section{CONSIDERAÇÕES FINAIS}

Apesar da matriz energética mundial ainda ser dominada pelas fontes não-renováveis, notadamente os combustíveis fósseis, a geração de energia por meio de fontes renováveis vem conhecendo um crescimento significativo nos últimos anos, alavancado pelos investimentos das potências econômicas globais, que são os maiores responsáveis pela poluição, mas que detêm os meios financeiros para investir em fontes alternativas. As promessas feitas e os compromissos firmados pelos países ajudam a alavancar essa mudança, essencial para viabilizar o desenvolvimento sustentável e para o combater as mudanças climáticas.

O horizonte das energias renováveis se mostra promissor, as fontes citadas nesse trabalho vêm despontando como os caminhos mais viáveis, resta a cada país investir naquela mais condizente com a sua realidade, de acordo com suas condições naturais e com a avaliação dos impactos sociais e ambientais que cada uma possa vir a causar.

O aumento da eficiência energética também é um fator de grande relevância, ao consumir menos recursos e reduzir os custos de geração de energia, importante para se garantir o acesso universal ao recurso e consequentemente melhorar as condições sociais e ambientais do planeta.

Todos os países devem avançar na utilização de fontes renováveis e investir em eficiência energética, principalmente as grandes potências mundiais, que são os maiores poluidores. É responsabilidade delas também cooperar para que países em desenvolvimento consigam mudar sua base energética e possam garantir o acesso de milhões de pessoas a formas 
renováveis modernas de energia. Apenas dessa forma será finalmente possível tornar a matriz energética mundial mais eficiente, limpa e renovável, reduzir com sucesso as emissões de CO2 e combater as mudanças climáticas.

\section{REFERÊNCIAS BIBLIOGRÁFICAS}

BRASIL. Balanço Energético Nacional 2015: Ano Base 2014. Empresa de Pesquisa Energética. Rio de Janeiro: EPE, 2015.

EVANS A., STREZOV V., EVANS T. J. Assessment of sustainability indicators for renewable energy technologies, in: Renewable and Sustainable Energy Reviews, vol. 13, p. 1082-1088, 2009.

GEA. 2013 Geothermal Power: International Market Overview. Washington, 2013.

GOLDEMBERG, José; LUCON, Oswaldo. Energias Renováveis: um futuro sustentável. Revista USP, São Paulo, n.72, p. 6-15, dezembro/fevereiro 2006-2007.

GWEC. Global Wind Energy Outlook. Bruxelas: GREENPEACE/GWEC, 2014.

IEA. Energy and Climate Change - World Energy Outlook Special Report. Paris: OECD/IEA, 2015

IEA. Energy Statistics Manual. Paris: OECD/IEA, 2005.

IEA. World Energy Outlook 2014: portuguese translation. Paris: OECD/IEA, 2014.

IHA. Hydropower Status Report. Londres: IHA Central Office, 2015.

IRENA. Ocean Energy Report. Bonn, 2014.

ONU. Povos Resilientes, Planeta Resiliente: um futuro digno de escolha. Nova York: Nações Unidas, 2012.

PNUMA. Rumo a Uma Economia Verde - Caminhos para o Desenvolvimento Sustentável e a erradicação da Pobreza - Síntese para Tomadores de Decisão. 2011. Disponível em: http://www.pnuma.org.br/publicacoes.php.

REN21. Renewables 2015 Global Status Report. Paris: REN21 Secretariat, 2015.

TAIOLI, Fabio. Recursos Energéticos. In: TEIXEIRA, Wilson et. al (Org.). Decifrando a Terra.

São Paulo: Companhia Editora Nacional, 2008. 